\title{
Biliary Gallbladder Cáncer
}

\author{
Dra Mirta D’Ambra* \\ Ministry of Health University of Buenos Aires, Argentina
}

Received: May 05, 2018; Published: July 11, 2018

*Corresponding author: Hiyam Al Haddad, Consultant Breast surgeon, Department of surgery, King Fahd hospital of the University, Saudi Arabia, Tel: +966505879917; Email: dr_hiyam@yahoo.com

\section{Introduction}

Gall bladder cancer (CVB) is a rare disease in the world and highly lethal. In 1777, Maximillian de Stoll made the first description in the famous Vienna Clinic. Keen in 1891 performs the first resection. In 1978, Piehler and Crichlow wrote the first large CVB study demonstrating 5\% survival (SV) in 5835 cases analysed). As early as 1931, Garretón Silva highlighted the high frequency of CVB when he described that in a series of 350 patients with acute cholecystitis, of them were affected by a malignant transformation. In most cases CVB is presented as an asymptomatic entity and only presents symptoms when there is advanced disease. The life forecast in all stages of the CVB is close to $5 \%$. The average life in patients diagnosed incidentally is 26.4 months. The CVB can be 6 times more common in women than in men. The incidence increases with age and is diagnosed more frequently between the sixth and seventh decade of life.

In relation to mortality, the CVB has one of the largest in the world with 15.6 and 7 per-100,000 inhabitants in women and men respectively, being the first cause of death in Chilean women on breast cancer, lung cancer and of the cervix. The highest rates are in regions of southern Chile, areas of high poverty, greater Amerindian population (Mapuche), insufficient access to health services including access to surgical services for cholecystectomy. The only symptoms are those usually caused by an existing cholelithiasis. CVB should be suspected in patients with cholelithiasis in whom, in the preoperative study, a vesicle with thickened walls appears on the ultrasound. In these cases, a computed tomography of the abdomen should be requested, to complete the study and plan the surgery

1. Ultrasonography (US): Magnetic nuclear resonance (NMR) in CVB.

2. Tumour markers.

3. Recently, studies show that the expression of CD34, CA15-3 and MIB-1 could help determine prognostic factors for the disease. In the case of CA 19-9, this marker is a marker of worse survival, although it is not specific in the diagnosis since it is elevated in other neoplastic pathologies. Another marker is over expression of the $\mathrm{p} 53$ gene, it is

\section{Tumour markers}

5. Recently, studies show that the expression of CD34, CA15-3 and MIB-1 could help determine prognostic factors for the disease. In the case of CA 19-9, this marker is a marker of worse survival, although it is not specific in the diagnosis since it is elevated in other neoplastic pathologies. Another marker is overexpression of the p53 gene, it is increased in CVB and in high-grade dysplasia's compared to benign lesions. Other markers such as ADAM-17, EGFR, TGF-á could also play a role in the prognosis.

6. increased in CVB and in high-grade dysplasia's compared to benign lesions. Other markers such as ADAM-17, EGFR, TGF-á could also play a role in the prognosis

\section{Metastasic Distribution}

The CVB presents a metastatic distribution by lymphatic, vascular, neural, intraperitoneal, intraductal and by contiguity. Within the lymphatic path, it follows 3 routes:

1. Right half of the hepatoduodenal ligament to the nodes of the cystic duct, pericoledocia and of the hepatic artery proper to retro pancreatoduodenal or retro portal until finally the paraaortic.

2. On the left it reaches the retro pancreaticoduodenal or retro portal nodes following medially through the hepatoduodenal ligament.

3. To the hepatic hilum from where it spreads throughout the Glisson's capsule. The main sentinel nodes are cystic, pericoleco-dia, retro portal and hilar. Regarding staging of patients with jaundice, cholangiography.

The study of distance dissemination is initially carried out using the imaging methods used to diagnose CVB. Other methods such as $18 \mathrm{~F}$-fluorodeoxyglucose positron emission tomography (PET) are not used routinely in the evaluation of distant dissemination, however there is evidence that it could be useful in the detection of distant metastases in patients with potentially resectable disease. 


\section{Treatment}

To plan the treatment, it must be considered, before the staging that, from the clinical point of view, there are patients with inapparent cancer, those who present as cholelithiasis, without suspicion of malignant tumour disease, in whom the postoperative biopsy reveals the presence of the tumour. In many of these cases, cholecystectomy, as we will see later, can be curative. Another group is presented as locally advanced, with compromise of the hepatic bed and the possible presence of regional adenopathy's, suspicious. In these patients it is important to rule out the intraoperative presence of metastases to continue with radical surgery. Finally, there is a group of patients with metastatic disease, whose therapeutic approach should be aimed at the histological confirmation of the tumour and metastatic lesions, to plan palliative therapies.

The therapeutic confrontation is determined, as we have previously indicated, by the CVB stage. T is (carcinoma in Situ) and $\mathrm{T} 1 \mathrm{a}$ (Tumour invades the lamina propria), are treated once the cholecystectomy has been performed. T1b (Tumour invades the muscular layer) and T2 (Tumour invades the peri muscular connective tissue without extension beyond the serosa or in the liver), require a wedge resection or an extended cholecystectomy to increase survival. This means the resection of at least $2 \mathrm{~cm}$ of liver from the vesicular bed in addition to a regional lymphadenectomy. There is recent evidence that in the cases of patients with stage I CVB (T1a and T1b), they would benefit in terms of survival when associating a portal lymphadenectomy. In the case of advanced tumours such as T2/T3 (tumour that perforates the serosa (visceral peritoneum) and/or directly invades the liver and/or another adjacent organ or structure such as the stomach, duodenum, colon, pancreas, omen to or extrahepatic bile duct ) with positive lymph nodes (N1), radical cholecystectomy is required, which includes subsegmental liver resection of segments IVB and V plus regional lymphadenectomy of the hepatoduodenal ligament, common hepatic artery and retro pancreatic lymph nodes. In the case of local dissemination of the infundibulum, vesicular neck or structures of the Calot triangle, some authors advocate a hepatic triseglycto-my, with resection of the bile duct.

In the case of T4 tumours, the most used surgery is palliative. In it a resection is performed in block with removal of all organs included. Some authors have shown an increase in 5-year survival when performing extensive resections that include hepatectomies associated with pancreatoduodenectomy. Neoadjuvant therapy in CVB is still under discussion. Radiotherapy (RT) shows only a survival benefit in cases of positive microscopic margins or in residual disease after resection.

Chemotherapy (QT) shows little impact on survival when combining 5-Fluorouracil (5-FU) with RT compared to patients who only received surgery. Therapies tested in other tumours (pancreas) with 5-FU and leucovorin, 3-AP, capecitabine, oxaliplatin and bevacizumab have been extrapolated to patients with CVB without showing relevant impact on survival. Some studies with Mitomycin C and 5-FU in cases of recurrence in para-aortic nodes would present an increase in global survival at 5 years. According to the NCCN recommendations, there is no randomized phase III study that indicates the use of an adjuvant QT regimen in patients who have already undergone surgery; however, it suggests the use of fluoropyrimidines (except in $\mathrm{T} 1 \mathrm{~b}$ N0 tumours) or the use of fluoropyrimidines or gem.

\section{Your next submission with Juniper Publishers will reach you the below assets}

- Quality Editorial service

- Swift Peer Review

- Reprints availability

- E-prints Service

- Manuscript Podcast for convenient understanding

- Global attainment for your research

- Manuscript accessibility in different formats ( Pdf, E-pub, Full Text, Audio)

- Unceasing customer service

Track the below URL for one-step submission https://juniperpublishers.com/online-submission.php 